\title{
Two Roads, One Destination: Community and Organizational Mechanisms for Contextualizing Child Abuse Prevention in Australia and the UK
}

\author{
Carlene Firmin $^{1}$ (D) Susan Rayment-McHugh ${ }^{2}$
}

Accepted: 1 May 2020 / Published online: 28 May 2020

(C) The Author(s) 2020

\begin{abstract}
Calls for a contextual approach to abuse prevention highlight a need to better understand how contextual frameworks may be operationalized. Using a dual-case study design, this research compares two contrasting pilot projects underpinned by contextual theories of abuse prevention. One was implemented in a small remote Indigenous community in Australia and aimed to reduce the extent of youth-perpetrated sexual abuse. The other occurred in a densely populated urban area in London (UK) and involved the co-creation and testing of a contextual child protection response to peerto-peer abuse. Despite their divergent approaches to developing contextual practice, a comparison of the two projects identified shared features of implementation. Both involved context-specific community buy-in and ownership of a response to peer-topeer abuse; solutions that were co-created between professionals and communities; and the enhancement of community guardianship, pro-social use of space, and changes to the physical design of areas to increase safety. Consequentially, both projects demanded a radical transformation in the way health and social care professionals viewed the target of their interventions - the what - and the approach to achieving change - the how. Comparing these two case studies provides a unique opportunity to extend knowledge on the practical application of contextual theoretical approaches to abuse prevention.
\end{abstract}

Keywords Child abuse $\cdot$ Prevention $\cdot$ Contextual approaches $\cdot$ Situational crime prevention

Carlene Firmin

carlene.firmin@beds.ac.uk

1 Institute of Applied Social Research, University of Bedfordshire, Luton, UK

2 Sexual Violence Research and Prevention Unit, USC School of Law \& Criminology, University of the Sunshine Coast, Sippy Downs, Queensland 4575, Australia 


\section{Introduction: Paving a Contextual Path}

The abuse of children is a global public health concern. Much abuse is perpetrated by adults known to those they harm, although there has been growing recognition over the past decade of the abuse of young people by same-aged peers (Ashurst and McAlinden 2015; Barter 2009; Finkelhor et al. in press; Firmin 2017b; Hackett 2014; Lloyd 2018). To date, most responses to child abuse have targeted the individuals involved, including largely individualized statutory child protection responses, individual-level treatment for identified perpetrators of abuse, and supportive counselling for victims. An emerging knowledge base, however, shows that contextual factors, such as peer relationships, school, neighborhood, and online settings, also contribute to abuse and protection. This highlights the relationship between person and context, and the need to consider context when seeking to prevent or respond to abuse (Allnock 2019; Barter 2009; Catch 22 2013; Firmin 2017b; Smallbone et al. 2013a). It is timely, therefore, to investigate the most effective ways to contextualize child abuse prevention. Against a backdrop of multi-disciplinary calls for a contextual narrative, and importantly, approach to practice, this study examines two independent pilot projects that mounted responses to the contextual dynamics of different forms of peer-to-peer abuse. Together, these case studies provide shared insights into community and organizational mechanisms for change through a contextual approach to prevention.

\section{Background: a Route Well-Trodden, but a Destination Not Reached}

The influence of contextual factors on behavior is not a new concept. Psychology has long acknowledged the relationship between individuals and their immediate environments. This formed one of the core psychological debates of the 1960s, regarding whether cross-situational consistency or situational specificity (variability) provided the best explanation for human behavior. Dispositional theorists reasoned that behavior was primarily driven by internal psychological constructs. Others maintained that behavior varied in response to the features of specific situations. In response to research which showed limited evidence of cross-situational consistency, a person-situation model was proposed by Mischel (1968). This model associated both individual and situational influences on behavior and their interaction.

Building on these foundations, social psychology research in the 1960s and 1970s extended the investigation of contextual influences on behavior. Zimbardo's (2004, 2007) famous (mock) Stanford Prison Experiment is one example. In this study, student volunteers were psychologically screened to exclude any pre-existing psychological problems, and then randomly assigned to roles as "prisoners" or "prison guards." Despite this prior screening, students assigned as "prison guards" soon engaged in abusive behaviors towards student "prisoners," who in turn responded submissively and displayed significant psychological distress. Following an escalation in these behavioral concerns, and a need to protect the well-being of student participants, the experiment was canceled less than half-way through its scheduled duration. Zimbardo concluded that the unique prison environment they created facilitated this out-ofcharacter behavior in the students. 
The discipline of environmental criminology builds on the same interaction between person and situation, with a particular focus on the effects of immediate environmental conditions on crime commission (Wortley and Mazerolle 2008). A strong criminology evidence-base supports this contention. For example, links have been established between accessibility and crime (e.g., increased property crime risks close to travel paths) (Armitage 2017). The effectiveness of situational crime prevention methods, which aim to reduce crime by altering aspects of the immediate environment, further supports this interactive relationship. For instance, research has associated reductions in vehicle theft to advances in car security (Webb 2010) and reductions in volatile substance misuse (petrol-sniffing) in remote Australian Indigenous communities with the introduction of "non-sniffable" Opal fuel (d'Abbs and MacLean 2011).

Environmental criminology is also concerned with concentrations of crime in certain places and at certain times (Eck et al. 2005; Lee et al. 2017), and thus in the "criminogenic" nature of the environments in which crime occurs. Sherman et al. (1989), for example, spatially examined over 300,000 police calls for service in a US city over a 12-month period, identifying "hot spot" street addresses for crime. They found only $3 \%$ of "places" were responsible for $50 \%$ of calls to police. This crime concentration at "places" is even more apparent when compared with previous research showing it required a greater number of individuals (10-18\%) to account for similar crime levels (Sherman 1995; Spelman and Eck 1989).

Social work, sociology, and social policy scholars have also articulated the relationship among context/environment, child abuse, and protection (Barter 2009; Featherstone et al. 2018; Hackett 2014; Jack and Gill 2010; Kimbrough-Melton and Melton 2015; Rogowoski 2012). Studies into intimate partner violence in young people's relationships have specifically identified peer group contexts and peer relationships as informing the nature of romantic relationships during adolescence (Barter 2009; Connolly et al. 2000; Corr 2012). Researches into gang-affiliation, peer-sexual abuse and sexual harassment at school, and fears of knife crime in local neighborhoods have all suggested that the physical design and cultural norms of school and community settings affect young people's sense of safety and can enable or frustrate the likelihood of abuse occurring (Catch 22 2013; Firmin 2017b; Lloyd 2018; Pitts 2013; Smallbone et al. 2013a). In reflecting on this evidence-base, social work scholars have consistently called for contextual, structural, and social responses to child abuse (Firmin 2020; Featherstone et al. 2018; Fenton 2016; Jack and Gill 2010; Wood and Tully 2006).

A strong evidence-base also now exists for the situational nature of child sexual abuse (CSA) (McKillop et al. 2019; Wortley and Smallbone 2006), including within organizational settings (Kaufman et al. 2016; Terry and Ackerman 2008). For example, Wortley and Smallbone (2006) argue the typical late onset of sexual offending, high offense versatility, and low recidivism rates contradict the idea of those who perpetrate abuse having strong deviant interests, suggesting other/additional factors must also contribute to abuse. Extending this work, Wortley and Smallbone (2006) developed a person-situation typology for sexual offense against children, identifying an individual's motivations as predatory, opportunistic, or situational in nature, and situations themselves as challenging, tempting, or precipitating. They argue that less criminally disposed individuals are more likely to react to situational triggers or exploit opportunities in their immediate environment, in order to perpetrate abuse. Explanations for concentrations of child sexual abuse also focus on criminogenic contextual conditions, 
rather than groups of highly motivated, deviant individuals (Rayment-McHugh et al. 2015a; Rayment-McHugh 2020). Collectively, these contextual conceptualizations reveal a need to limit opportunities for abuse, enhance guardianship in high-risk contexts, and to address social norms and other contextual factors that might facilitate or normalize abuse (Rayment-McHugh et al. 2015a).

Despite this strong multi-disciplinary, conceptual, and empirical evidence-base linking context with behavior (including abuse), poor knowledge to practice transfer is evident in the fields of both psychology and social work. Indeed, protective and correctional services and clinical practice have largely remained focused on understanding and responding to individuals. Social work models in a range of countries, including the USA, the UK, and Australia, have focused on child and family interventions to prevent abuse (Featherstone et al. 2018; Fenton 2016; Lloyd et al. 2019; Parton 2014), neglecting to actively engage with the wider neighborhood contexts found to be relevant in supporting families to protect children (i.e., Jack and Gill 2010; KimbroughMelton and Melton 2015). This narrow lens has applied even when mounting responses to extra-familial forms of abuse. In such cases, protective services either fail to intervene (focusing only on abuse within families) or intervene by focusing on how parenting can reduce risks of extra-familial abuse, rather than assessing and intervening with the peer, school, and neighborhood contexts in which such abuse often occurs.

\section{Method: Mapping the Road Ahead}

\subsection{Study Design}

A cross-national, comparative case study design was adopted to explore the application of contextual frameworks to the prevention of child abuse. Case study research involves the in-depth analysis of a "case" to advance understanding (Merriam 1998; Stake 1995), and is recognized as a valuable methodology for examining complex social issues within real-world settings (Yazan 2015). Case study research is particularly suitable for investigating process issues (Lauckner et al. 2012), hence its relevance for examining the application of contextual prevention frameworks.

Two case studies, comprising independent pilot research projects led by the authors, were selected for this study, each representing exemplars of a contextual approach to prevention and intervention. Despite being implemented in diverse locations, each shared underlying contextual frameworks and was a response to peer-to-peer abuse. This study explored how contextual frameworks were operationalized in the two case studies, addressing two key research questions: (a) how were contextual frameworks applied and implemented in these case studies and (b) what are the key change mechanisms in a contextualized approach to abuse prevention?

Case study data were drawn from existing project documents and reports (e.g., Contextual Safeguarding Network 2019; Neighborhoods Project 2017). Four criteria were selected to guide comparisons between the two case studies: approach, project design, prevention activities, and evaluation. These criteria were developed with practitioner input, to represent key considerations in project implementation. 


\subsection{Case Studies}

The two case studies comprise independent pilot projects, implemented in diverse contexts. Despite being implemented on different sides of the world, both were concerned to address and prevent youth-perpetrated abuse that was largely occurring in extra-familial contexts, particularly institutions such as schools and public spaces including parks and alleyways. Components of the two pilot projects are summarized in Table 1.

Case Study A The Neighborhoods Project (NP), led by Grififith University in Australia, aimed to prevent endemic youth-perpetrated sexual violence and abuse in identified communities of concern. One of these communities was a small (population of approximately 1200), remote (road access only during the "dry season") Aboriginal community in far-northern Australia. Within this community, problems of sexual behavior between children and older peer-to-peer sexual abuse were revealed in a range of public and organizational settings, including at the local school, in a local park, and behind vacant public buildings. Youth involved ranged in age from early childhood to late adolescence. Peer norms supported under-age and abusive sexual behavior, with breakdowns in guardianship and place management providing opportunities for abuse to occur. Much of this behavior was not reported to police or statutory authorities (Smallbone et al. 2013a). The NP team consisted of two experienced psychologists, supported by a team of academics with expertise spanning sexual violence prevention, situational crime prevention, and evaluation research. The psychologists worked in close partnership with local community members and other stakeholders, and delivered key prevention activities in the field. This project operated between 2013 and 2019.

Case Study B The Contextual Safeguarding (CS) Program, led by the University of Bedfordshire1, approached similar community challenges in a densely populated,

Table 1 Key components of the two case studies

\begin{tabular}{|c|c|c|}
\hline & Case study A: Neighborhoods Project & Case study B: Contextual Safeguarding Program \\
\hline Country & Australia & UK \\
\hline Setting & Small remote Aboriginal community & Highly population urban metropolitan district \\
\hline Discipline & Psychology/criminology & Social work \\
\hline Problem & $\begin{array}{l}\text { Harmful sexual behavior in children } \\
\text { and peer-to-peer sexual abuse in } \\
\text { public and organizational settings }\end{array}$ & $\begin{array}{l}\text { Escalation of sexual abuse and violence among } \\
\text { young people in extra-familial settings; } \\
\text { limited capacity of child protection } \\
\text { authorities to address this risk }\end{array}$ \\
\hline Aim & $\begin{array}{l}\text { Reduce the extent of youth-perpetrated } \\
\text { sexual abuse in this community }\end{array}$ & $\begin{array}{l}\text { Extend the reach of child protection authorities } \\
\text { and establish safeguarding process to address } \\
\text { abuse of youth in extra-familial contexts }\end{array}$ \\
\hline Targets & Contextual risks & Contextual risks \\
\hline Project team & $\begin{array}{l}\text { Field psychologists working with community } \\
\text { members and a team of academics with } \\
\text { expertise in abuse prevention }\end{array}$ & $\begin{array}{l}\text { Researchers working with one local authority } \\
\text { in London }\end{array}$ \\
\hline
\end{tabular}


urban metropolitan (London) setting. Over a decade, public and political concerns about weapon use, sexual exploitation, and criminal exploitation among young people had escalated (Home Affairs Select Committee 2019; ITV News 2018; Jay 2014; NCA 2017). Behaviors included contact sexual offense, sometimes in exchange for money, drugs, or protection; the sharing of or threats to share, indecent images of young people with their peers; the coercion of young people into transporting and distributing drugs around the UK, including the forced "plugging" of these drugs; and serious violence, including weapon-enabled crime.

These issues were characterized by their occurrence in extra-familial settings, including schools, parks, high streets, and youth clubs, which existed beyond the families that had been the traditional target of child protection interventions. While much of this abuse was perpetrated by other young people (peer-to-peer), adults were also exploiting young people in extra-familial settings. Children's services were struggling to create safety for young people who were relatively protected in their families but at risk of significant harm in their communities, with increasing numbers coming into statutory care due to extra-familial risks (ADCS 2018; Hill 2019; Home Affairs Select Committee 2019; Jay 2014).

Following case review and action research activities across multiple sites (Firmin et al. 2016), researchers worked with one urban local authority to extend the reach of its children's services beyond families and into extra-familial contexts where harm was occurring. Historically, when a child was at risk of significant harm, children's services focused on increasing the protective capacity of families to prevent abuse; in the CS project, they would be concerned with increasing the protective capacity of young people's peers, schools, and neighborhoods to address abuse occurring in those contexts; this would involve extending their assessments and intervention plans to those contexts, and not just the children and families affected by them.

The CS team in the test site consisted of three social workers, three youth workers, and a clinical psychologist, supported by an embedded researcher, research assistant, and senior academic lead. Together they applied a Contextual Safeguarding framework (Firmin 2017a) to create a child protection system that could accept referrals for and assess and intervene with community/education contexts and peer relationships associated with extra-familial abuse. This project commenced in 2017 and is ongoing.

\subsection{Ethics and Limitations}

Each research team received ethical approval from their respective universities to undertake these two pilot projects. These approvals were current throughout project delivery, data collection, and analysis.

While a case study approach has proved useful for deepening how contextual approaches are understood, there are also limitations to the data presented. Primarily, these two case studies are not representative of wider contexts; findings do not suggest the approaches presented are replicable in other community or practice settings. Secondly, both studies have been subject to initial evaluation, but require longitudinal analysis to more fully understand the impact of these approaches. Both of these limitations are managed in the presentation of the study findings, discussion, and recommendations: calling for contextually driven approaches in onward testing and a wider pool of research, to further the knowledge presented here. 


\section{Results: Two Roads}

Both similarities and differences are noted between the two case studies, in the contextualization of abuse prevention. Despite shared features of project design and similar evaluation outcomes, the two case studies deviate in their overall approach and in the precise prevention activities adopted. Project differences largely reflect local context. Comparative criteria for the two cases are presented in Table 2.

Both case studies demonstrate a pressing need to address abuse affecting young people in neighborhood, school, and peer settings; however, they took distinctly different roads to address those concerns.

\subsection{Approach Taken to Address Contextual Risks}

In case study A, clinical staff had received a series of referrals for individual youth adjudicated for sexual offense and had been working with these youth and their families, in their local community. During the course of this work, community members raised concerns about the safety of children and youth from peer sexual abuse, beyond discrete referred youth, with subsequent investigation into the dynamics and dimensions of the problem, corroborating community concerns (Smallbone et al. 2013a). The Neighborhoods Project (NP) was instigated directly in response to these concerns. Community leaders worked collaboratively with project members, sharing decision-making and guiding implementation and evaluation. In this way, the NP was initiated and supported by the community, rather than being initiated and led by government authorities.

Community involvement grew naturally and was considered critical to the successful implementation of a comprehensive prevention agenda in an Indigenous community context. Indeed, understanding this context was important to project design, as damaging colonization experiences among Australia's Aboriginal and Torres Strait Islander populations (including dispossession, displacement, forced removal of children, and marginalization) has led to an enduring mistrust of statutory authorities (Dudgeon et al. 2010). This in turn produces significant barriers to disclosure and help-seeking from the key government agencies with responsibility for child safety (Willis 2011). In similar remote community contexts, alternative top-down approaches have been criticized for

Table 2 Comparative components of the two case studies

\begin{tabular}{|c|c|c|c|c|}
\hline & $\begin{array}{l}\text { Case study A: Neighbourhoods } \\
\text { Project }\end{array}$ & $\begin{array}{l}\text { Case study B: Contextual } \\
\text { Safeguarding Program }\end{array}$ & Shared & Different \\
\hline Approach & Community led & Statutory led & & $\checkmark$ \\
\hline Project design & $\begin{array}{l}\text { Suite of activities to address } \\
\text { local contextual risks and make } \\
\text { places safer }\end{array}$ & $\begin{array}{l}\text { Suite of activities to address local } \\
\text { contextual risks and make places } \\
\text { safer }\end{array}$ & $\checkmark$ & \\
\hline $\begin{array}{l}\text { Prevention } \\
\text { activities }\end{array}$ & $\begin{array}{l}\text { Environmental assessments, } \\
\text { training programs to build } \\
\text { guardianship capacity }\end{array}$ & $\begin{array}{l}\text { Contextual assessment, high risk } \\
\text { locations targeted by child } \\
\text { protection authorities }\end{array}$ & & $\checkmark$ \\
\hline Evaluation & Promising & Promising & $\checkmark$ & \\
\hline
\end{tabular}


their lack of community consultation. The "Northern Territory Emergency Response" is one such example, where endemic sexual violence in remote Aboriginal communities was addressed via compulsory health checks for children, quarantining welfare payments, increasing police numbers, and deploying the Australian Army (Evans 2012; Gray 2015, 2016).

To promote cultural safety, the NP followed guidelines for best practice and research with Aboriginal and Torres Strait Islander peoples and communities (e.g., AIATSIS 2012; Price-Robertson et al. 2011). Community engagement and adequate time for community consultation were prioritized to ensure issues were understood from a community and cultural perspective. Project team members worked alongside the local community to develop prevention activities from the ground up, and built relationships and trust with community members. This ensured a community voice across all aspects of the project. Community input and involvement came to define the project: working "with" the community to enhance safety, rather than providing a service "to" the community. This community engagement and mobilization is central to community crime prevention methods (Bullock and Fielding 2017), and considered key to effective practice with Australian Aboriginal and Torres Strait Islander peoples (Homel et al. 1999). Only after this community engagement was established did the project turn its focus to engaging other local services and statutory authorities. This included the development of collaborative partnerships with police, education, health, child protection, and justice authorities.

In contrast, in case study B, CS was first tested across a social work system in an urban local authority area in London (Firmin et al. 2016). Researchers within the CS team worked alongside social work and youth work practitioners to develop this new approach to addressing extra-familial risk, which required whole-systems change in the way child protection services were understood and utilized. The project focused on child protection systems as national policy was increasingly naming extra-familial harm as a child protection issue, and one that social workers should play a key role in addressing. From 2009 onwards, government departments issued safeguarding guidance related to different forms of extra-familial harm, and a year into the CS project, all forms of extra-familial harm had been inserted into statutory child protection guidelines, requiring all social work departments in England to respond to the young people affected by them.

The CS project responded to this requirement by creating local safeguarding systems that could target the context (and social conditions) associated with risks for abuse; do this through the lens of child protection and child welfare (as opposed to crime reduction or community safety); create change through partnerships between social workers and those with a reach into extra-familial contexts (such as security guards, transport providers, housing staff, teachers); and measuring success in relation to whether safety has increased in contexts where young people are spending their time - rather than solely focusing on how young people behave in contexts that remain unsafe.

The design and evaluation of the approach required buy-in and engagement from social workers at the outset, having been offered in response to concerns that they were being tasked with safeguarding young people from extra-familial risks within a system originally intended to address intra-familial abuse. While a need for social workers to improve responses to extra-familial risk had been identified, they required support to 
create practice approaches that would leverage these desired improvements and address the shortcomings of the system in which they operated. Care was needed to ensure that the inclusion of extra-familial harm into child protection systems did not lead to unnecessary increases in the numbers of young people and families open to children's social care, but instead ensured that young people who were being abused in extrafamilial settings received the protection they required, and the contexts where they were harmed were also attended to (thus safeguarding a wider group of young people who may be in those contexts but not open to children's social care). The co-created nature of CS, and its foundations within child welfare traditions, became fundamental to how it was understood and replicated.

While social workers were, therefore, the principal partner in this project, they coordinated plans that featured input from the police, housing, youth work, health, and education among others; this mirrored how they supported families. For example, social workers were coordinating plans for some families where there were ongoing police investigations related to child abuse. In other cases, they were working with families where there was no police involvement, but housing and domestic abuse services were playing a key role in supporting the children to thrive. For all families, children's services played a role in coordinating support in response to concerns about child abuse and child welfare - the police were involved in some, but not all, of these plans: the same principle was applied to extra-familial harm.

\subsection{Project Design}

Despite being implemented in different communities and approached in different ways, the two projects shared many components characteristic of a contextual response to abuse. Both projects followed a series of steps to (i) identify and understand issues at a local level and their contextual nature; (ii) plan an approach to address the issues identified in consultation with local (professional or community) partners; (iii) implement a suite of activities to impact change; and (iv) monitor the progress being made (Contextual Safeguarding Network 2019; Rayment-McHugh et al. 2015b).

All prevention activities implemented in case study A (NP) were designed to address local manifestations of the problem, informed by a thorough contextual assessment, which considered when, where, and how abuse occurred, along with risk and protective factors spanning family, peer, and neighborhood systems (Smallbone and RaymentMcHugh 2013; Smallbone et al. 2013b). Investigation of the dynamics and dimensions of the problem helped to identify when most peer-to-peer abuse occurred, settings in which abuse was committed, social contexts which precipitated abuse, and barriers to effective guardianship (Rayment-McHugh et al. 2015b). Each could then be targeted through discrete prevention initiatives.

In this case study, community leaders actively participated in project design and decisions about which activities to implement, in collaboration with core project staff. This collaboration included consultation on the content of each activity and advice about where, when, and how to deliver specific prevention programs. Community advisors also provided important local contextual and cultural information critical to ensuring each activity best reflected and was tailored to local culture and community conditions. 
Active community engagement was prioritized, to promote and maintain community trust in project staff and ensure larger-scale community buy-in. To achieve this, a "Neighborhood Survey" was undertaken seeking information from community members regarding concerns for child and youth safety, general youth behavior and relationship standards, and ideas for addressing risks for sexual abuse. Results revealed important information to guide prevention planning, ensuring a community voiceinformed project design and subsequent implementation (Neighborhoods Project 2017). NP staff also routinely participated in community activities, to enhance their accessibility to community members. They responded personally to all community members willing to speak about concerns for youth safety. Following the establishment of strong community engagement and partnerships, the NP subsequently built strong partnerships with multi-disciplinary non-government, local council, and state and federal government agencies. Project team members met regularly (in person) with local community partner organizations to discuss project activities and engage in collaborative planning and implementation where relevant. Written reports were also provided in some instances.

Implementation in this case also required attention to local cultural beliefs, protocols, and traditions. This included a thorough knowledge of local customs, including both historical and contemporary issues, in addition to knowledge of local sexual abuse problems. Ensuring prevention activities respected these cultural issues was important for community acceptance. Each activity was also designed specifically for the local context, using suitable modalities and local terminology and incorporating local case examples. Cultural supervision was undertaken by the project psychologists to enhance culturally respectful and effective engagement. Efforts were also made to learn the local dialect, to improve communication between project staff and community members.

There are similarities here with case study B. The CS framework, and all the structures, resources, and practices that have been built to bring it to life, have been (and continue to be) operationalized, and further developed, within local contexts. In contrast to the NP, however, the research team running the CS project needed buy-in from the professional (social work) community to test and embed the approach into children's services. Social workers needed a sense of ownership and had to be assured of the relevance and usefulness of the approach at a time when budgets were being stretched, caseloads were increasing, and there were mounting political pressures to effectively safeguard adolescents (i.e., ADCS 2018; Jay 2014; Ofsted 2011).

This professional community buy-in and collaboration was achieved in three phases. Firstly, local authorities audited their response to peer-to-peer abuse, in partnership with the research team, and developed a set of action plans to explicitly address extrafamilial contexts within their assessment and intervention models. This learning was then applied in one London local authority. This phase saw the first attempt at creating a CS child and family system. Finally, members of a virtual practitioners' network drew upon iterative learning from the official test site and published resources, to run their own test-site work on identified extra-familial contexts (both schools and public spaces) where young people encounter abuse. Across these three phases, there has been a gradual shift from researchers leading, but working with, practitioners (phase one), to joint ownership and development of practices between researchers and practitioners (phase two), through to practitioner-led testing (phase three), with researchers providing advice at a distance. 
All elements of the CS framework, including prevention activities and resources, were co-created with social workers and then tested with wider partners-including young people, residents, parents, business owners, school leaders, police, and health agencies among others. Researchers worked at the same desks as social workers attended meetings with them, observed them speaking with residents, survey businesses, and engage with families. This approach ensured the research team understood the language, practice cultures (such as reflective and strengths-based approaches facilitated via social work units in this site), and expectations of the social work community, and could work within this environment to develop CS practices.

Development of the CS framework required strong partnerships between researchers and social workers, and between social workers and the wider statutory, voluntary, and increasingly private sector organizations. For example, if concerns were raised about young people being groomed into exploitation at a shopping center, partnerships were required between social workers, the police, specialist exploitation practitioners from community organizations, store managers, and security guards to assess the shopping center and collectively action measures to increase safety and protective cultures. In order to further embed the approach, relationships have also been built with policymakers who have responsibility for child protection policy, regulation, and legislation.

\subsection{Prevention Activity Examples}

In both case studies, a suite of prevention activities were developed and implemented to address contextual risks at the local level. These initiatives were designed to specifically address local risks, and thus differed across the two projects.

As an example, in case study A (NP), multiple strategies were initiated to address risks for problem sexual behavior and peer-to-peer abuse occurring at the local school, primarily aimed at enhancing effective guardianship in this setting and reducing opportunities for abuse to occur. Activities spanned primary, secondary, and tertiary levels of prevention, across different "targets" including the school setting itself, and vulnerable children and youth at this location (Smallbone and Rayment-McHugh 2017). For example, a training program was developed specifically for teachers in this remote Indigenous school setting, to build guardianship capacity to identify and respond effectively to concerning sexual behaviors, and to promote classroom-based, and whole-of-school, prevention strategies. An environmental assessment was undertaken of school buildings and grounds, to identify potential safety risks, including barriers to effective guardianship, and to make recommendations for physical changes that could improve safety, based on crime prevention through environmental design principles (e.g., Cozens et al. 2005). A parenting program was developed specifically for parents in this community, conceptualized as a method to equip parents with the skills to identify and address risks for sexual abuse both within and external to the family home (e.g., Prinz et al. 2009). This also built their capacity to engage with teachers about children's safety. Shared language and content between the teacher training program and the parenting program ensured clear and consistent messages for children and youth about sexual behavior. Police implemented targeted foot patrols (in community locations/times of greatest concern; identified through community consultation, police intelligence, and observational data), to enhance guardianship (Allard 
et al. 2018; Koper 1995; Sherman et al. 2014). This extended youth safety beyond school hours. Clinical programs were also available for identified children and youth with persistent concerning behavior. Each of these discrete prevention activities was designed to independently improve safety but also to complement each other, with collective interplay theorized to enhance overall effects. Each of the activities was also aligned with prevention activities targeting other community settings (for example, home environments and public spaces), to enhance overall impact.

In case study B (CS), the social work team became aware that a young man had experienced serious violence in an identified housing estate. Looking at the young man's referral, it appeared that the estate itself was experiencing chronic and repeated acts of violence. Police had investigated this violence and community safety partners were aware of the concerns. However, the wider welfare of young people on the estate had not been assessed. Given the mounting concerns, the social worker supporting the young man made a context referral about the estate, i.e., a referral to raise concerns about this context and not solely the individual young people who had been harmed within it.

The housing estate was referred into the child protection system, the referral was screened, and, given the levels of violence experienced by young people on the estate, it was evident that this was a context in which they were at risk of significant harm. A contextual assessment of the housing estate was initiated, led by a social worker in partnership with housing staff, the youth service, and community groups, to explore the welfare of young people on the estate. Assessment information was gathered via a residents' survey, observation of the location and mapping out identified areas of concern, sharing an area map with young people to gauge their sense of safety within the estate, and mapping the dynamics of a specific peer group who were encountering, and posing a risk of, harm on the estate. The information garnered through this process was analyzed via three areas of assessment: the needs and experiences of the population in this context (i.e., the estate); the level and nature of available guardianship (including that provided by residents, business owners, statutory services connected to the space); and wider environmental factors of relevance.

The contextual assessment investigated whether these issues were driven by behaviors/needs of the population in this context, the level or quality of guardianship, or wider environmental factors - such as chronic drug dealing, poor lighting - that are conducive with such harm. During this assessment, social workers identified the need to increase community guardianship and confidence among residents, and to reclaim unsafe spaces within the estate by using them for positive activities. More importantly, it identified that the dynamics at play within this young person's peer group contributed to this risk and that wherever that peer group travelled, it was possible similar risks would emerge. It was surprising to learn that the peer group actually spent time on this particular estate because they felt safe there - it was designed in a way that they had good line of sight should rival groups approach them and could get out easily if they needed to; this was not the same on other estates. This assessment process was distinct from previous practice-where social workers had assessed the individual young person referred into their service and the capacity of his parent to keep him safe from harm (and whether challenges at home were contributing to his risks in the community), rather than assess the context of harm itself. 
These matters were discussed at a planning meeting, chaired and managed in a model that mirrored a child protection "conference" to discuss a family assessment. Individuals in attendance were people who could influence the nature of the housing estate and address concerns identified during the assessment. Following this meeting, an intervention plan was developed, overseen by a social worker and delivered by a multi-agency team of professionals in partnership with residents. The lead social worker liaised with local police and community safety agencies to mitigate the risks of duplication and to ensure the child welfare plan for the estate ran alongside any policing activity or investigations that were underway. The plan included community guardianship training for local residents and business owners; the development of a parent support group, involving local community organizations, focused on parenting during adolescence, and the nature of harm in the local area; targeted interventions with individuals in a bid to alter the dynamics of the peer group associated with the concerns; and design changes to the housing block. Each activity on the plan was intended to address a concern about the estate and in doing increase the safety of the young person initially referred for support as well as their wider peer network.

\subsection{Evaluation}

Both projects have been subject to pilot evaluation based on administrative, survey, clinical, and interview data sources, using an iterative process of review and refinement. Given the inherent challenges in evaluating projects aiming to address complex social problems, and relatively short implementation time frames to date, it is too early to report on ongoing or long-term impacts on the lives of young people, families, and communities. Realistically, a much longer implementation and evaluation period will be required before definitive outcomes on a larger scale can be achieved (Lefevre et al. forthcoming; Tilley et al. 2014). Preliminary evaluation across both projects, however, suggests these contextual approaches show promise. Specifically, discrete prevention activities have delivered progress towards improved safety (mapped against program logic), and project activities have been well received by both professional and community partners (see Neighborhoods Project 2017; Contextual Safeguarding Network 2019). Further to this, the co-created nature of approaches in both projects means that some elements are supported through an action-research approach, with assessment and intervention methods being designed, reviewed, and amended throughout the lives of the projects to ensure their fit (and benefit) to local partners.

While further evaluation of these approaches is required, importantly, evaluation efforts to date, across both approaches, have facilitated new insight into mechanisms of change and the implementation of contextual approaches to abuse prevention. Key findings highlight the need to (a) identify (contextual) factors contributing to abuse at a local level and develop evidence-informed preventive initiatives to directly target these factors; (b) work in close collaboration with community and/or multi-disciplinary professional partners to promote change; and (c) have local context inform project design and implementation. Both community and organizational change mechanisms provide a viable approach. Context was fundamental to both "what" was targeted in preventive initiatives and "how" this was implemented. In this way, context is fundamental to both change targets and implementation design. 


\section{Discussion: One Destination}

There is much about these two case studies that make them distinct. They originated in different countries and within distinct disciplines (predominantly psychology and social work). Most significantly, each case study adopted divergent approaches to creating contextual impact. With one program delivered in a remote Indigenous community in Australia and the other in an urban setting in the UK, different approaches to design and implementation should be expected, with context at the core of contextual prevention. In practice, this meant contextual factors informed the design of initiatives, in addition to their targets. Case study A, for example, grew organically from community concerns about peer-to-peer sexual violence and abuse. This community involvement defined central features of this approach and informed its development. In contrast, case study B grew from research that identified the contextual dynamics of peer-to-peer abuse were not being addressed by traditional child protection services. This triggered a process of system reform and the establishment of a pilot project led by child protection services, broadening their practice to accommodate and respond to extra-familial contexts. This demonstrates the versatility of contextual theories for informing safeguarding initiatives in this field.

And yet each project started with a shared concern—extra-familial abuse-and reached a shared destination - a contextual suite of interventions within a largely individualized field of practice. They were also both underpinned by contextual theories - albeit stemming from different academic disciplines. These theories emphasize situational and broader ecological influences on behavior, including the perpetration of abuse and violence, highlighting a need to address the contextual dynamics of abuse in order to enhance individual safety. Combined program logic for both approaches is displayed in Fig. 1.

These common foundations, and the extra-familial nature of the harm being addressed, enabled each project to design approaches that focused on "place" rather than "people" as a route to abuse prevention. By achieving this, each project achieved

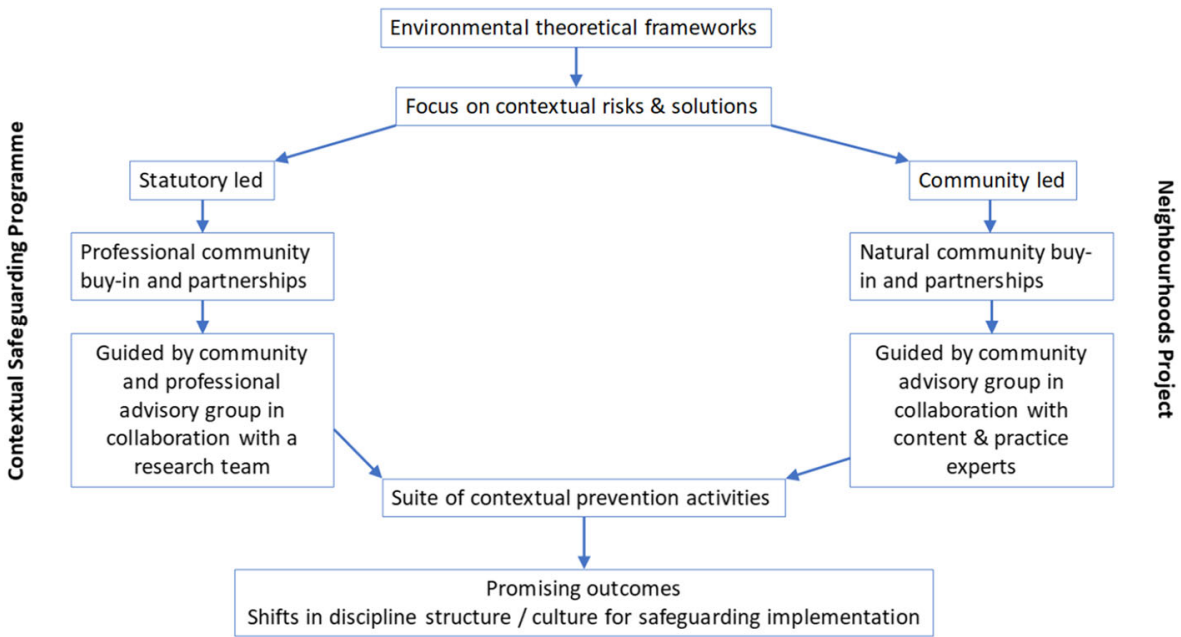

Fig. 1 Combined program logic for both approaches 
contextual outputs within largely individualized professions (psychology and social work), suggesting wider system change within those professions (and their respective research communities) for the approach to be embedded. In this sense, they shared "one destination": amending systems, creating partnerships, and challenging professional processes that had traditionally focused on individuals so they were equipped to address the contextual dynamics of harm. Thus, in both their design and delivery, these projects required, and simultaneously enabled, changes in the perspective and mindset of project participants. They strove to create safer places for children and youth, not simply safer individuals, as a route to abuse prevention.

\section{Conclusion: The Road Ahead}

This shared destination has surfaced further questions about the future of each approach independently and collaboratively, and whether they might be applied to other forms of abuse beyond those tested so far.

Both projects were focused on abuse that occurred in organizational and public settings and were therefore well suited to testing approaches that targeted those specific contexts as part of a response. In some respects, it can feel like common sense: if violence is associated with extra-familial contexts, those contexts need to be addressed as part of the solution. However, wider arguments have been made by others for also seeing abuse within domestic settings through a contextual lens (e.g., Featherstone et al. 2018), arguing that what happens in families is also informed by the contexts in which they live their lives. As such, there is room to investigate further whether the approaches developed in these projects in response to extra-familial harm may also be of relevance to harm that is intra-familial.

In terms of the future for each approach, CS draws child protection services, and social workers specifically, into fields of practice that have been traditionally reserved for criminal justice agencies as well as youth and community groups. England's policy climate created the conditions that both required and enabled this move; but further work is needed to understand the implications of social work involvement in nonfamilial settings. For some, the approach will align well with community social work, radical and structural social work traditions (Fenton 2016; Rogowoski 2012), if it remains focused on addressing the contextual dynamics of abuse rather than increasing state intervention in the lives of individuals; further testing and embedding are required to resolve this. In the case of the NP, a lack of social work involvement has raised different questions. Crucially, the contextual approach it promotes was led by community groups, who worked alongside researchers, psychologists, and police. There has been less adoption or leadership by wider statutory partners. As such, it has not started to characterize wider systems that respond to these issues, which remain focused on individuals, and has struggled with sustainability in such a climate.

While these two projects provide useful guidance for future efforts to contextualize abuse prevention, the remaining question for policy and practice professionals who choose to employ a contextual approach is how best to implement, and sustain, such practice. The community focus of the NP approach may be well placed to address abuse in marginalized communities, or with minority populations, who may face barriers to help seeking and engagement with statutory authorities, or where cultural 
considerations are paramount. In contrast, the CS approach perhaps provides a more central model for sustaining and scaling up contextual approaches, given the role of statutory agencies in responding to issues of child safety. No doubt there are also other possible iterations of contextual approaches that may better suit other local contexts. While diverse contextual dimensions may demand different approaches, in the long run, a combination of the statutory developments achieved by the CS project and community buy-in and collaborative leadership that characterized the NP approach may address the questions each project is respectively left with. Current discussions are exploring opportunities to draw the two approaches together in one test site in future.

Even at this stage, however, each project respectively, and both projects collectively, signal a need for further evidence on contextual interventions to child abuse- - within research and practice fields that are dominated with de-contextualized evidence bases and individual assessments and interventions. This paper does not suggest that such contextual work replace 1:1 support for children and families, rather that such work could be bolstered through consistent attention being paid to the social conditions of such abusive incidents. The relative paucity of contextual research in the child abuse field will hamper further efforts to advance practice. It is critical, therefore, that researchers contribute to a deeper knowledge base from which contextual prevention activities can be designed.

Acknowledgments We gratefully acknowledge the National Lottery Community Fund, the Samworth Foundation, the Esmee Fairbairn Foundation, Ashoka UK, and numerous children's services departments for their support of the Contextual Safeguarding Programme, and the Queensland and Australian Governments for funding the Griffith Neighborhoods Project. This article describes the authors work on these two projects. The views expressed are the responsibility of the authors and do not necessarily reflect the views of the aforementioned organizations.

\section{Compliance with Ethical Standards}

Conflict of Interest The authors declare that they have no conflict of interest.

Disclaimer The views expressed are the responsibility of the authors and do not necessarily reflect the views of the aforementioned organizations.

Open Access This article is licensed under a Creative Commons Attribution 4.0 International License, which permits use, sharing, adaptation, distribution and reproduction in any medium or format, as long as you give appropriate credit to the original author(s) and the source, provide a link to the Creative Commons licence, and indicate if changes were made. The images or other third party material in this article are included in the article's Creative Commons licence, unless indicated otherwise in a credit line to the material. If material is not included in the article's Creative Commons licence and your intended use is not permitted by statutory regulation or exceeds the permitted use, you will need to obtain permission directly from the copyright holder. To view a copy of this licence, visit http://creativecommons.org/licenses/by/4.0/.

\section{References}

ADCS. (2018). Safeguarding pressures phase 6. Manchester: ADCS.

AIATSIS. (2012). Guidelines for ethical research in Australian indigenous studies. Australian institute of aboriginal and torres strait islander studies: Canberra. Accessed from https://aiatsis.gov. $\mathrm{au} /$ sites/default/files/docs/research-and-guides/ethics/gerais.pdf. 
Allard, T., Stewart, A., \& Manning, M. (2018). The virtues of rubbish research: A novel way of measuring the impact of crime prevention interventions in public spaces. In G. Farrell \& A. Sidebottom (Eds.), Realist evaluation for crime science. (chapter 6). London, UK: Routledge.

Allnock, D. (2019). 'Snitches get stitches': School-specific barriers to victim disclosure and peer reporting of sexual harm committed by young people in school contexts. Child Abuse and Neglect, 89, 7-17.

Armitage, R. (2017). Design, crime and the built environment. In. In N. Tilley \& A. Sidebottom (Eds.), Handbook of crime prevention and community safety (pp. 234-253). Oxon: Routledge.

Ashurst, L., \& McAlinden, A.-M. (2015). Young people, peer-to-peer grooming and sexual offending: Understanding and responding to harmful sexual behaviour within a social media society. Probation Journal, 62(4), 374-388.

Barter, C. (2009). In the name of love: Partner abuse and violence in teenage relationships. British Journal of Social Work, 39, 211-233.

Bullock, K., \& Fielding, N. (2017). Community crime prevention. In N. Tilley \& A. Sidebottom (Eds.), Handbook of crime prevention and community safety (pp. 87-108). Oxon: Routledge.

Catch 22. (2013). The role of the family in facilitating gang membership, criminality and exit. London: Catch 22.

Connolly, J., Papler, D., Craig, W., \& Taradash, A. (2000). Dating experiences of bullies in early adolescence. Child Maltreatment, 5(4), 229-310.

Contextual Safeguarding Network. (2019). Contextual safeguarding implementation toolkit. Luton: University of Bedfordshire.

Corr, M. L. (2012). From boys to men: Phase two findings. Manchester: University of Manchester.

Cozens, P., Saville, G., \& Hillier, D. (2005). Crime prevention through environmental design (CPTED): A review and modern bibliography. Property Management, 23(5), 328-356.

d'Abbs, P., \& MacLean, S. (2011). Petrol sniffing interventions among Australian indigenous communities through product substitution: From skunk juice to opal. Substance Use \& Misuse, 46(sup 1), 99-106. https://doi.org/10.3109/10826084.2011.580223.

Dudgeon, P., Wright, M., Paradies, Y., Garvey, D., \& Walker, I. (2010). The social, cultural and historical context of aboriginal and torres strait islander Australians. In N. Purdie, P., Dudgeon, \& R. Walder (Eds.), Working together: Aboriginal and torres strait islander mental health and wellbeing principles and practice (pp. 25-42). Canberra: Australian Council for Educational Research.

Eck, J. E., Chainey, S., Cameron, J. G., Leitner, M., \& Wilson, R. E. (2005). Mapping crime: Understanding hot spots. Washington DC: National Institute of Justice.

Evans, B. W. (2012). Northern territory emergency response: Criticism, support and redesign. Australian Journal of Rural Health, 20, 103-107. https://doi.org/10.1111/j.1440-1584.2012.01265.x.

Featherstone, B., Gupta, A., Morris, K., \& White, S. (2018). Protecting children: A social model (1st ed.). Bristol: Policy Press.

Fenton, J. (2016). Values in social work: Reconnecting with social justice. London: Palgrave.

Finkelhor, D., Shattuck, A., Turner, H., \& Hamby, S. (in press). A Behaviourally specific, empirical alternative to bullying: Aggravated peer victimisation. Journal of Adolescent Health. https://oi. org/10.1016/j.jadohealth.2016.05.021.

Firmin, C. (2017a). Contextual safeguarding: An overview of the operational, strategic and conceptual framework. Luton: University of Bedfordshire.

Firmin, C. (2017b). Abuse between young people: A contextual account. Oxon: Routledge.

Firmin, C. (2020). Contextual safeguarding and child protection: Rewriting the rules. Oxon: Routledge.

Firmin, C., Curtis, G., Fritz, D., Olatain, P., Latchford, L., Lloyd, J., \& Larasi, I. (2016). Towards a contextual response to peer on peer abuse. Luton: University of Bedfordshire.

Gray, S. (2015). The northern territory intervention: An evaluation. Retrieved from Monash University website: https://www.monash.edu/data.assets/pdf_file/0008/406943/Caitlin-edit-of-NT-Interventionpage-1.pdf.

Gray, S. (2016). Scoring the intervention: Fail grades on closing the gap, human rights. Indigenous Law Bulletin, 8(23), 10-14. Availability: https://search.informit.com.au/documentSummary;dn=062791557365731;res= IELIND>ISSN:062791557361328-062791557365475.

Hackett, S. (2014). Children and young people with harmful sexual behaviours. Dartington: Research in Practice.

Hill, N. (2019). Serious case review - Chris. London: Newham Safeguarding Children Board.

Home Affairs Select Committee. (2019, 01. 29.). Home affairs committee oral evidence: Serious violence, HC 1016. Retrieved 02. 04., 2019, from http://data.parliament.uk/writtenevidence/committeeevidence. svc/evidencedocument/home-affairs-committee/serious-violence/oral/95627.html. 
Homel, R., Lincoln, R., \& Herd, B. (1999). Risk and resilience: Crime and violence prevention in Aboriginal communities. Australian \& New Zealand Journal of Criminology, 32(2), 182-196.

ITV News. (2018). Headteachers struggle to get support for vulnerable and exploited children. Retrieved 01. 31., 2019, from https://www.gettyimages.co.uk/detail/video/headteachers-struggle-to-get-support-forvulnerable-and-news-footage/1053878896.

Jack, G., \& Gill, O. (2010). The role of communities in safeguarding children and young people. Child Abuse Review, 19, 82-96.

Jay, A. (2014). Independent inquiry into child sexual exploitation in Rotherham (1997-2013). Rotherham: Rotherham LSCB.

Kaufman, K., Erooga, M., Stewart, K., Zatkin, J., McConnell, E., Tews, H., \& Higgins, D. (2016). Risk profiles for institutional child sexual abuse: A literature review. Sydney Australia: Royal Commission into Institutional Responses to Child Sexual Abuse.

Kimbrough-Melton, R. J., \& Melton, G. B. (2015). "Someone will notice, and someone will care": How to build strong communities for children. Child Abuse and Neglect, 41, 67-78.

Koper, C. S. (1995). Just enough police presence: Reducing crime and disorderly behavior by optimizing patrol time in crime hot spots. Justice Quarterly, 12(4), 649-672.

Lauckner, H., Paterson, M., \& Krupa, T. (2012). Using constructivist case study methodology to understand community development processes: Proposed methodological questions to guide the research process. The Qualitative Report, 17(25), 1-22.

Lee, Y., Eck, J. E., \& O, S., \& Martinez, N. N. (2017). How concentrated is crime at places? A systematic review from 1970 to 2015. Crime Science, 6(6). https://doi.org/10.1186/s40163-017-0069-x.

Lefevre, M., Preston, O., Hickle, K., Horan, R., Drew, H., Banerjee, R., Cane, T., Barrow, M., \& Boyer, S. (forthcoming). Evaluation of the implementation of a contextual safeguarding system in the London Borough of Hackney. London: Department for Education.

Lloyd, J. (2018). Abuse through sexual image sharing in schools: Response and responsibility. Gender and Education., 1-19. https://doi.org/10.1080/09540253.2018.1513456.

Lloyd, J. \& Firmin, C. (2019). No further action: Contextualising social care decisions for children victimised in extra-familial settings. Youth Justice. https://doi.org/10.1177/1473225419893789.

McKillop, N., Rayment-McHugh, S., Smallbone, S., \& Bromham, Z. (2019). Part B - Chapter 4; Understanding and preventing the onset of child sexual abuse in adolescence and adulthood. In M. Phelan (Ed.), Crime \& Justice Research 2019. Special reports. Canberra: Australian Institute of Criminology https://aic.gov.au/publications/special/crime-and-justice-research-2019.

Merriam, S. B. (1998). Qualitative research and case study applications in education. San Francisco, CA: Jossey-Bass.

Mischel, W. (1968). Personality and assessment. New York: John Wiley \& Sons.

NCA. (2017). County lines, violence, exploitation and drug supply: National briefing report. London: National Crime Agency Retrieved from http://www.nationalcrimeagency.gov.uk/publications/832county-lines-violence-exploitation-and-drug-supply-2017/file.

Office for Standards in Education, Children's Services and Skills (Ofsted). (2011). Ages of concern: Learning lessons from serious case reviews. London: Ofsted.

Parton, N. (2014). The politics of child protection. London: Palgrave.

Pitts, J. (2013). Drifting into trouble: Sexual exploitation and gang affiliation. In M. Melrose \& J. Pearce (Eds.), Critical perspectives on child sexual exploitation and related trafficking (pp. 23-37). Basingstoke: Palgrave Macmillan.

Price-Robertson, R., McDonald, M., Lewis, P., \& Bamblett, M. (2011). Working with indigenous children, families, and communities: Lessons from practice. Communities and Families Clearinghouse Australia (CAFCA) practice sheet. Accessed from https://aifs.gov.au/cfca/sites/default/files/publicationdocuments/ps6.pdf.

Prinz, R. J., Sanders, M. R., Shapiro, C. J., Whitaker, D. J., \& Lutzker, J. R. (2009). Population-based prevention of child maltreatment: The U.S. triple P system population trial. Prevention Science, 10, 1-12.

Project, N. (2017). Preventing youth sexual violence and abuse in Aurukun and West Cairns: Neighbourhoods Project implementation and evaluation report. Final report to the Australian department of the prime minister and cabinet (unpublished).

Rayment-McHugh, S. (2020). The uneven distribution of child sexual abuse. In Bryce, I., \& Petherick, W. (Eds). Childhood sexual abuse: Forensic issues in evidence, impact and management. US: Academic Press/Elsevier. (in press).

Rayment-McHugh, S., Smallbone, S. W., \& Tilley, N. (2015a). Endemic sexual violence and abuse: Contexts and dispositions. International Journal for Crime, Justice and Social Democracy, 4(2), 111-124. https://doi.org/10.5204/ijcjsd.v4i2.233. 
Rayment-McHugh, S., Adams, D., Wortley, R., \& Tilley, N. (2015b). Think global act local: A place-based approach to sexual abuse prevention. Crime Science, 4(22), 1-9. https://doi.org/10.1186/s40163-0150035-4.

Rogowoski, S. (2012). Social work with children and families: Challenges and possibilities in the neo-liberal world. British Journal of Social Work, 42, 921-940.

Sherman, L. W., Gartin, P. R., \& Buerger, M. E. (1989). Hot spots of predatory crime: Routine activities and the criminology of place. Criminology, 27(1), 27-55. https://doi.org/10.1111/j.1745-9125.1989.tb00862.x.

Sherman, L. (1995). Hot spots of crime and criminal careers of places. In J. Eck \& D. Weisburd (Eds.), Crime and place: Crime prevention studies 4 (pp. 35-52). Monsey, NY: Willow Tree Press.

Sherman, L. W., Williams, S., Ariel, B., Strang, L. R., Wain, N., Slothower, M., \& Norton, A. (2014). An integrated theory of hot spots patrols strategy: Implementing prevention by scaling up and feeding back. Journal of Contemporary Criminal Justice, 30(2), 95-122. https://doi.org/10.1177/1043986214525082.

Smallbone, S. W., \& Rayment-McHugh, S. (2013). Preventing youth sexual violence and abuse: Problems and solutions in the Australian context. Australian Psychologist, 48, 3-13. https://doi.org/10.1111/j.17429544.2012.0007.

Smallbone, S. W., \& Rayment-McHugh, S. (2017). Sexual crimes. In N. Tilley \& A. Sidebottom (Eds.), Handbook of crime prevention and community safety (pp. 439-453). Oxon: Routledge.

Smallbone, S. W., Rayment-McHugh, S., \& Smith, D. (2013a). Preventing youth sexual violence and abuse in west cairns and aurukun: Establishing the scope, dimensions and dynamics of the problem. Brisbane: Griffith University.

Smallbone, S. W., Rayment-McHugh, S., \& Smith, D. (2013b). Youth sexual offending: Context, goodenough lives, and engaging with a wider prevention agenda. International Journal of Behavioral Consultation and Therapy, 8(3-4), 49-54.

Spelman, W., \& Eck, J. E. (1989). Sitting ducks, ravenous wolves, and helping hands: New approaches to urban policing. Public Affairs Comment, 35, 1-9.

Stake, R. E. (1995). The art of case study research. Thousand Oaks, CA: SAGE Publications.

Terry, K. J., \& Ackerman, A. (2008). Child sexual abuse in the catholic church: How situational crime prevention strategies can help create safe environments. Criminal Justice and Behaviour, 35(5), 643-657.

Tilley, N., Rayment-McHugh, S., Smallbone, S., Wardell, M., Smith, D., \& Wortley, R. (2014). On being realistic about reducing the prevalence and impacts of youth sexual violence and abuse in two Australian indigenous communities. Learning Communities: International Journal of Learning in Social Contexts, $14,6-27$.

Webb, B. (2010). Steering column locks and motor vehicle theft: Evaluations from three countries. In R. V. Clarke (Ed.), Situational crime prevention: Successful case studies (2nd ed., pp. 46-58). Boulder, CO: Lynne Rienner Publishers.

Willis, M. (2011). Non-disclosure of violence in Australian indigenous communities. Trends \& issues in crime and criminal justice. Retrieved from the Australian Institute of Criminology website: https://aic.gov. au/publications/tandi/tandi405.

Wood, G., \& Tully, C. (2006). The structural approach to direct practice in social work: A social constructionist perspective (3rd ed.). New York: Columbia University Press.

Wortley, R., \& Mazerolle, L. (2008). Environmental criminology and crime analysis (pp 1-18). UK: Willan Publishing.

Wortley, R., \& Smallbone, S. W. (2006). Applying situational principles to sexual offences against children. In R. Wortley \& S. W. Smallbone (Eds.), Situational prevention of child sexual abuse (Vol. 19, pp. 7-35). Monsey, NY: Criminal Justice Press.

Yazan, B. (2015). Three approaches to case study methods in education: Yin, merriam, and stake. The Qualitative Report, 20(2), 134-152 Retrieved from https://nsuworks.nova.edu/tqr/vol20/iss2/1.

Zimbardo, P. (2004). A situationist perspective on the psychology of evil. In A. G. Miller (Ed.), The social psychology of good and evil (pp. 21-50). New York: Guilford.

Zimbardo, P. (2007). The lucifer effect: Understanding how good people turn evil. New York: Random House Trade Paperbacks.

Publisher's Note Springer Nature remains neutral with regard to jurisdictional claims in published maps and institutional affiliations. 